$5-5-2020$

\title{
Effectiveness, safety, and acceptability of medical abortion at home vs. in the clinic: An updated systematic review in response to COVID-19
}

Katherine Gambir

Camille Garnsey

Kelly Ann Necastro

Thoai Ngo

Population Council

Follow this and additional works at: https://knowledgecommons.popcouncil.org/departments_sbsr-pgy

Part of the Social and Behavioral Sciences Commons

How does access to this work benefit you? Let us know!

\section{Recommended Citation}

Gambir, Katherine, Camille Garnsey, Kelly Ann Necastro, and Thoai Ngo. 2020. "Effectiveness, safety, and acceptability of medical abortion at home vs. in the clinic: An updated systematic review in response to COVID-19," COVID-19 Research \& Evaluations. New York: Population Council. 
Effectiveness, safety, and acceptability of medical abortion at home vs. in the clinic: an updated systematic review in response to COVID-19

Protocol

May 4, 2020

Authors: Katherine Gambir ${ }^{1}$, Camille Garnsey ${ }^{1}$, Kelly Ann Necastro², Thoai D. Ngo ${ }^{1,3}$

\section{Affiliations:}

${ }^{1}$ Poverty, Gender and Youth Program, Population Council, New York, New York, USA ${ }^{2}$ Massachusetts General Hospital, Boston, Massachusetts, USA. ${ }^{3}$ The GIRL Center, Population Council, New York, New York, USA

\section{Corresponding author:}

Katherine Gambir

Poverty, Gender, and Youth Program

kgambir@gmail.com

\section{POPULATION COUNCIL}

IDEAS. EVIDENCE. IMPACT.

One Dag Hammarskjold Plaza

New York, NY 10017

www.popcouncil.org

Description: This document describes the protocol for an updated systematic review of the evidence comparing medical abortion practiced at home and in clinics in terms of effectiveness, safety and acceptability. We are updating Ngo et al.'s 2011 review given the importance of access to homemedication abortion during the COVID-19 pandemic. We will conduct a systematic search for randomized controlled trials and prospective cohort studies comparing home-based and clinic-based medical abortion. Successful abortion is the main outcome of interest. Side-effects, complications, and acceptability are secondary outcomes. Risk Ratios (RRs) and their $95 \%$ confidence intervals (Cls) will be calculated. Estimates will be pooled using a random-effects model. 


\section{INTRODUCTION}

\section{Rationale}

Medical abortion is a non-surgical pregnancy termination option that involves using a combination of mifepristone and misoprostol, or misoprostol only, to end a pregnancy. The current World Health Organization (WHO) guidelines advise a combination protocol for abortions less than 12 weeks of gestation that involves an initial dose of mifepristone followed by a dose of misoprostol 24-48 hours later (1). Of the estimated 55 million abortions that occur world wide each year, 25 million (45\%) are estimated to be unsafe, with most unsafe abortions occurring in low-resource settings (2). However, an increasing reliance on medical abortion methods worldwide have been associated with an increase in the rates of safe abortion, and a decline in the rates of morbidity and mortality associated with abortion (3-5). Additionally, in the thirty years since mifepristone was first approved as an abortifacient, research has shown the method to be safe, effective, and acceptable to women in a range of settings (6-10). A growing body of evidence also suggests that women with access to adequate information, high-quality drugs, and facility based care can manage their own abortions with little or no healthcare provider supervision, yet access to medical abortion continues to be limited by laws, regulations, and medical guidelines that restrict who can administer the drugs, where administration can take place, and how the drugs can be administered (11-15).

On March 11, 2020, the WHO declared COVID-19, a viral disease that began spreading in Wuhan, China in January of 2020, a global pandemic (16). Following the declaration, governments across the world moved aggressively: instituting nationwide lockdowns and extensive travel restrictions, and urging citizens to practice social distancing to slow the spread of the disease (17). Health systems worldwide have been burdened by the pandemic as facilities have struggled to keep pace with the rate of virusrelated hospitalizations, the rapid spread of the disease among healthcare professionals, and shortages of personal protective equipment (18-20). The necessary but drastic restrictions on movement and daily life have the unintended consequence of further limiting access to other essential healthcare services, including abortion. To reduce the spread of coronavirus and alleviate burdens on health care systems and frontline healthcare workers, it is critical to limit physical interactions between individuals seeking abortions and providers as much as possible.

Expanding access to home-based abortion care is an important strategy for protecting abortion access while slowing the spread of the deadly virus and reducing burdens on healthcare systems, especially in settings where capacity and workforces are already strained and limited. Home-based medical abortion most often entails a health-care provider administering mifepristone at the clinic, and the pregnant person taking misoprostol later in the privacy of their own home with any desired members of their support network. The model requires fewer clinic visits, alleviating burdens on health care facilities and providers, and limiting points of contact $(14,21)$.

Governments in the UK and Northern Ireland have already recognized the potential for home use of medical abortion to reduce the burden on healthcare systems in light of COVID-19 and shifted regulation to allow for home-based care $(22,23)$. On the other hand, legislators in six states in the United States have sought to freeze abortion services indefinitely by including abortion on the list of "non-essential healthcare" that must be delayed until shut-down orders are lifted (24). Similarly, activists in Slovakia 
and Italy are urging their governments to make similar designations and a bill in Poland aimed at further restricting abortion was recently re-introduced in the parliament there(25). These policies and efforts, many of which continue to be challenged in court, ignore global public health expertise and medical guidance that clearly designate abortion as a time sensitive and essential service (26).

In 2011, Ngo et. al published a systematic review of the evidence on the efficacy, safety, and acceptability of home-administered medical abortion compared to clinic-based medical abortion. The review suggested that there is no difference in the effectiveness or acceptability of home-based medical abortion compared to clinic-based medical abortion, and that home-based abortion is safe (27). Since the publication of this review, the evidence on home-based medical abortion has grown. A recently published systematic review found no difference in effectiveness between self-administered and provider-administered abortions, where all participants who self-administered did so at home (28). Additionally, recent studies have demonstrated that women prefer home-administration to clinic-based care for reasons related to control and privacy (29-35), and it is likely that such preferences are more pronounced due to concerns around contracting or spreading COVID-19. However, the WHO and the majority of health officials around the world have not yet issued guidelines on the option of home-/selfadministration of medical abortion to protect healthcare workers and ensure access to abortion care.

Given the growing body of evidence from the past decade and the importance of access to home-based medical abortion in the context of the COVID-19 global health and economic crisis, it is critically important to reexamine and update this body of literature to provide a conclusive evidence base for health officials across the globe to refer to during and post pandemic.

\section{Objective}

This review examines published literature on the evidence on the effectiveness, safety, and acceptability of medical abortions performed at home in comparison to medical abortions performed in clinics or other health care facilities.

\section{METHODS}

\section{Eligibility Criteria}

We will search for published studies on home-based administration of medical abortion that test different regimens (e.g. mifepristone, or misoprostol, or both), routes of administration, and doses. Randomized and non-randomized controlled trials (RCTs and NRCTs) (clustered or non-clustered) and prospective cohort studies with a concurrent comparison group, that compare the safety, or effectiveness, or both, of home-based medical abortions to clinic-based medical abortion, will be eligible for inclusion. We will search without language restrictions.

The inclusion criteria for studies include:

1. a comparison between home-based administration of medical abortion and clinic-based administration of medical abortion;

2. a prospective assessment of outcomes; and

3. recruitment of women who are seeking an abortion. 
Ideas. Evidence. Impact.

\section{Types of participants}

Studies recruiting women of any age, in any setting, who are seeking an induced abortion, and provide informed consent, are eligible for the review. We will exclude studies recruiting women with missed, incomplete abortion, or intrauterine fetal death from the review. Studies will be eligible irrespective of the gestational age of the fetus, and we will explore the possible impact of this variable on the results by subgroup analysis, as gestational age has been identified as a known confounder, with higher gestational ages indicating lower efficacy of medical abortion $(27,36)$.

\section{Types of interventions}

Studies comparing induced medical abortion with mifepristone-misoprostol or misoprostol-only administered at home versus induced medical abortion with mifepristone-misoprostol or misoprostolonly in the clinic. The only administration route (for home and clinic-based administration) for mifepristone is oral. Possible home and clinic-based administration routes for misoprostol include oral, sublingual, buccal, and vaginal. Repeat doses of misoprostol may occur.

\section{Primary outcomes}

The primary outcome is success of medical abortion (with success defined as uterine evacuation without the need for surgical intervention).

\section{Secondary outcomes}

The secondary outcomes are:

1. serious complications;

2. side effects of medical abortion, which may include nausea, heavy bleeding, diarrhea, fever/chills, pain/cramps, and vomiting; and

3. acceptability, as defined by women's level of satisfaction with the medical abortion process, likelihood of selecting the same medical abortion method again, likelihood of recommending method to a friend, and likelihood of selecting home use or clinic use for future medical abortion; and

4. companionship during home administration of misoprostol.

Serious complications are rare (27) however, complications have been reported on, and therefore are important to document.

Reporting of the secondary outcomes listed here will not be an inclusion criterion for the review and we will include studies regardless of the whether they assessed the secondary outcomes.

\section{Data Collection}

\section{Search Strategy}

Our search strategy for this review will build on the search Ngo et al. conducted for the original homeadministration review, as well as a recently conducted search for a review of self-administered vs. 
provider administered medical abortion $(27,28)$. We will adapt the search terms used in these reviews to ensure we find all relevant studies. We will search the following electronic databases for relevant trials: the Cochrane Central Register of Controlled Trials via the Cochrane Register of Studies Online (CRSO) web platform (from inception on-wards) (MEDLINE Epub Ahead of Print, In-Process \& Other NonIndexed Citations Ovid (from inception onwards) Embase Ovid (1980 onwards) (and CINAHL (Cumulative Index to Nursing and Allied Health Literature) Ebsco (from 1982 onwards).

We will search the following trial registers for ongoing and registered trials: ClinicalTrials.gov and WHO ICTRP (who.int/ictrp). We will also search Google Scholar for recent trials not yet indexed in the major databases.

We will also hand search reference lists of relevant trials and systematic reviews retrieved by the search to identify eligible RCTs and prospective cohort studies of home-administration of medical abortion with a concurrent comparison group and contact experts in the field to obtain additional data. We will also hand search the following websites for relevant articles: Guttmacher Institute, Gynuity, International Consortium for Medical Abortion, Ipas, Marie Stopes International, and the Population Council.

\section{Draft of Search Terms}

Below is a preliminary draft of the search strategy we will use when searching the Cochrane Central Register of Controlled Trials:

1 exp Abortion, induced/ or Abortion, legal/ or Abortion, criminal/ or Abortion, septic/ or Abortion, therapeutic/ or Abortion applicants/

2 (abortion* or ((medical* or trimester* or gestation* or pregnan*) adj5 terminat*) or "uterine evacuation*").tw.

3 or/1-2

4 Abortifacient agents/ or Abortifacient agents, nonsteroidal/ or Abortifacient agents, steroidal/ or Mifepristone/ or Misoprostol/

5 (Abortifacient* or Mifepristone* or Misoprostol* or RU486 or RU-486 or "abortion pill" or Cytotec or GyMiso or Korlym or Mifegyne or Mifeprex or Misodel).tw.

\section{6 or/4-5}

7 Self administration/ or Self medication/ or Nurse Midwives/ or Pharmacies/ or Physicians/ or exp Health personnel/

8 (self* or herself or themselves or chemist or chemists or clinic or clinician* or drugstore* or "drug store*" or home or home-use or home-based or

midwife or midwives or nurse* or OTC or "over the counter" or pharmacies or pharmacist* or pharmacy* or physician* or provider*).tw.

\section{9 or/7-8}

10 and $/ 3,6,9$ 


\section{Selection process}

After two independent reviewers conduct an initial screen of titles and abstracts retrieved by the search, we will retrieve the full texts of all potentially eligible studies. We will correspond with study investigators, as necessary, to clarify study eligibility. Disagreements will be resolved by discussion. If any reports require translation, we will describe the process used for data collection. We will document the selection process with a PRISMA diagram $(37,38)$.

\section{Data extraction and management}

Two review authors will independently screen and extract data from eligible studies using a data extraction form designed and pilot-tested by the authors. Any disagreements will be resolved by discussion. Data extracted will include study design and key features of studies.

\section{Data items}

We will extract the following data during our review:

1. Population. Mean gestational age; mean patient age; percentage married; primigravida measured by percentage; percentage of women who experienced their first abortion in this study; and mean years of education will be extracted from the studies. We will also extract data on the percentage and number of women who were lost to follow-up and the number and percentage of women who self-selected into each group for non-randomized studies.

2. Intervention. We will record the description of the intervention including the drugs used, dosage, number of doses, and routes of administration, as well as each study's inclusion and exclusion criteria. Drug regimens include either mifepristone-misoprostol or misoprostol-only. We will extract data on each dose of each drug measured in mcg or $\mathrm{mg}$, as well as the route of administration for each dose (e.g. oral, sublingual, buccal, or vaginal). We will include administration in a health facility followed by administration at home.

3. Comparison groups. Comparison groups will include those who underwent a medical abortion in a health facility. We will record the number of women recruited to each comparison group and the number of complete abortions and extract the same data points for both intervention and comparison groups.

\section{Outcomes and Prioritization}

The proportion of women with successful medical abortion (uterine evacuation without the need for surgical intervention) is the primary outcome, and therefore, the most important outcome in this review. We will extract data on serious complications and side effects (including nausea, heavy bleeding, diarrhea, fever/chills, pain/cramps, and vomiting) reported in the studies, describe how each were defined and documented, and summarize the findings. We will also extract data on acceptability, including the number and proportion of women who were satisfied or highly satisfied with the method; the number and proportion of women who would choose the method again; the number and proportion of women who would select home use or clinic use for future medical abortion; and the number and 
proportion of women who would recommend the method to a friend. Finally, we will extract data on companionship among home-use participants.

Where studies have multiple publications, we will collate multiple reports of the same under a single study ID with multiple references. We will correspond with study investigators for further data on methods, results, or both, as required.

\section{Data Analysis}

\section{Risk of bias in included studies}

Two review authors will independently assess included RCTs and NRCTs for quality of the evidence and risk of bias using the GRADE criteria (e.g., risk of bias, consistency of effect, imprecision, indirectness, and publication bias). We will assess the risk of bias for our primary outcome of successful abortion (39). Two review authors will work independently to judge the evidence quality (e.g. high, moderate, low, or very low) and disagreements will be resolved by discussion. The review authors will justify, document, and incorporate their judgments into reporting the results for the successful abortion outcome. We will analyze the risk of bias for high-quality and low-quality studies in combination and separately to minimize risk of bias. We will also address risk of bias for NRCTs by controlling for gestational age in our analysis, as it has been found to be an important confounder of successful abortion; previous reviews found lower efficacy in more advanced pregnancies (36).

\section{Measures of treatment effect}

For dichotomous outcomes (e.g. successful abortion, any complication requiring hospitalization, among others), we will use the number of events in the control (clinic-based) and intervention (home-based) groups of each study to calculate Mantel-Haenszel risk ratios (RRs). We will present $95 \%$ confidence intervals $(\mathrm{Cls})$ for all outcomes in our main effects analysis and for two secondary outcomescomplications and acceptability. We will calculate the risk of having a successful abortion using the number of women recruited for each study and an intention-to-treat approach where possible. Where data to calculate RRs or mean differences (MDs) are not available, we will use the most detailed numerical data available that may facilitate similar analyses of included studies (e.g. test statistics, $P$ values). We will assess whether the estimates calculated in the review for individual studies are compatible in each case with the estimates reported in the study publications. We will also control for gestational age in our analysis of non-randomized studies (28.)

\section{Assessment of heterogeneity}

We will assess statistical heterogeneity with $\mathrm{Chi}^{2}$ and $\mathrm{I}^{2}$ statistics, using a cut-off point of $\mathrm{P}<0.10$ to indicate statistical heterogeneity, and we will use the $\mathrm{I}^{2}$ statistic to quantify heterogeneity. We will use the Cochrane Handbook criteria for interpreting $I^{2}$ values (38).

\section{Data synthesis}

For studies determined to be sufficiently similar regarding participants, interventions, comparisons, and outcomes, we will conduct a meta-analysis. We will combine data using a random-effects model to obtain an overall summary. We are selecting this model a priori to incorporate the effect of trial 


\section{POPULATION}

COUNCIL

Ideas. Evidence. Impact.

heterogeneity among prospective studies from different settings (27). We will present a forest plot showing a RR and $95 \% \mathrm{Cl}$ for the primary outcome of successful abortion. We will group RCTs and NRCTs separately when summarizing the effect size of our primary outcome, and in combination for our secondary outcomes related to side effects, complications, and acceptability. We will report a narrative synthesis for any outcomes for which insufficient data are found for meta-analysis, including incomplete reporting on the outcomes of interest. We will document and summarize data on dosage, number of doses of mifepristone/misoprostol, and route of administration (e.g. oral, sublingual, buccal, or vaginal) to compare by mode of administration (home versus clinic).

We will combine the results to find a common effect across those studies by conducting a meta-analysis. We will perform statistical analysis using RevMan Web (41).

\section{Subgroup analysis and investigation of heterogeneity}

If we detect substantial heterogeneity, we will explore possible explanations in subgroup analyses. When interpreting the results, we will take any statistical heterogeneity into account, especially if there is any variation in the direction of the effect.

As applicable, we will conduct subgroup analyses for the primary outcome measure within the following subgroups (where data are available).

1. By gestational age (e.g. $<9$ weeks, 9 to 12 weeks, and $\geq 12$ weeks).

2. Low- to middle-resource settings versus high-resource settings (as defined by the study authors).

\section{Sensitivity analysis}

We will conduct sensitivity analyses to assess heterogeneity and the effect of risk of bias in the included studies, comparing studies rated at high or low risk of bias for each assessed item. We will also conduct a separate analysis of high-quality studies (i.e., RCTs) to explore the effect of biases on study heterogeneity.

\section{Overall quality of the body of evidence}

We will use the GRADE to assess the overall quality of the evidence (39). Given that standard practice is to take the lowest quality of evidence from all the critical outcomes assessed, and we are only using GRADE to assess one outcome (our primary outcome of successful abortion), the overall quality rating we provide will mirror our quality assessment for the outcome of successful abortion.

\section{Results}

\section{Proposed Tables and Figures}


Table 1. List of databases and search terms used in systematic review comparing home-based and clinicbased medical abortion

\begin{tabular}{|l|l|l|l|l|l|}
\hline Search & Cochrane & MEDLINE & Ovid & CINAHL & Ebsco \\
\hline 1 & & & & & \\
\hline 2 & & & & & \\
\hline Results & & & & & \\
\hline
\end{tabular}

Table 2. Rates of successful abortion in studies comparing home-based and clinic-based medical abortion included in systematic review

\begin{tabular}{|c|c|c|c|c|c|c|c|c|}
\hline \multirow[t]{2}{*}{ Study } & \multirow[t]{2}{*}{$\begin{array}{l}\text { Mifepristone } \\
\text { dose (mg); } \\
\text { misoprostol } \\
\text { dose }(\mu \mathrm{g}) \text {, } \\
\text { [supplementary } \\
\text { dose]; route }\end{array}$} & $\begin{array}{l}\text { No. of } \\
\text { women } \\
\text { recruited } \\
\text { (no. lost } \\
\text { to } \\
\text { follow- } \\
\text { up) }\end{array}$ & $\begin{array}{l}\text { Complete } \\
\text { abortion, } \\
\text { no. (\%) }\end{array}$ & \multirow[t]{2}{*}{$\begin{array}{l}\text { Complete } \\
\text { abortion } \\
\text { RR }(95 \% \\
\mathrm{Cl})\end{array}$} & \multirow[t]{2}{*}{$\begin{array}{l}\text { Max. } \\
\text { Gestational } \\
\text { age }\end{array}$} & \multirow[t]{2}{*}{$\begin{array}{l}\text { Contact } \\
\text { with } \\
\text { health } \\
\text { services }\end{array}$} & \multirow[t]{2}{*}{$\begin{array}{l}\text { Women } \\
\text { accompanied } \\
\text { during home } \\
\text { administration } \\
\text { of misoprostol } \\
\text { (\%) }\end{array}$} & \multirow[t]{2}{*}{$\begin{array}{l}\text { Comparative } \\
\text { participant } \\
\text { characteristics } \\
\text { at baseline }\end{array}$} \\
\hline & & \begin{tabular}{l|l}
$\mathrm{H}$ & $\mathrm{C}$
\end{tabular} & $\mathrm{H}$ & & & & & \\
\hline
\end{tabular}

${ }^{*} \mathrm{C}$, clinic; $\mathrm{Cl}$, confidence interval; $\mathrm{H}$, home; $\mathrm{RR}$, risk ratio; ${ }^{*} P<0.05$.

Table 3. Side-effects, their duration and the proportion of women who reported them among those who underwent home-based and clinic-based medical abortion

\begin{tabular}{|c|c|c|c|c|c|c|c|c|c|c|c|c|c|c|c|}
\hline \multirow[t]{4}{*}{ Study } & \multicolumn{15}{|c|}{ Side-effect } \\
\hline & \multicolumn{3}{|c|}{ Pain/Cramps } & \multicolumn{3}{|c|}{ Nausea } & \multicolumn{3}{|c|}{ Vomiting } & \multicolumn{3}{|c|}{ Fever/chills } & \multicolumn{3}{|c|}{ Heavy bleeding ${ }^{a}$} \\
\hline & \multicolumn{2}{|c|}{$\begin{array}{l}\text { Mean } \\
\# \text { of } \\
\text { days } \\
\text { (SD) }\end{array}$} & $\begin{array}{l}\% \text { who } \\
\text { reported }\end{array}$ & \multicolumn{2}{|c|}{$\begin{array}{l}\text { Mean } \\
\text { \# of } \\
\text { days } \\
\text { (SD) }\end{array}$} & $\begin{array}{l}\% \text { who } \\
\text { reported }\end{array}$ & \multicolumn{2}{|c|}{$\begin{array}{l}\text { Mean } \\
\# \text { of } \\
\text { days } \\
\text { (SD) }\end{array}$} & $\begin{array}{l}\% \text { who } \\
\text { reported }\end{array}$ & \multicolumn{2}{|c|}{$\begin{array}{l}\text { Mean } \\
\text { \# of } \\
\text { days } \\
\text { (SD) }\end{array}$} & $\begin{array}{l}\% \text { who } \\
\text { reported }\end{array}$ & \multicolumn{2}{|c|}{$\begin{array}{l}\text { Mean } \\
\# \text { of } \\
\text { days } \\
\text { (SD) }\end{array}$} & $\begin{array}{l}\% \text { who } \\
\text { reported }\end{array}$ \\
\hline & $\mathrm{H}$ & C & & $\mathrm{H}$ & C & 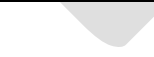 & $\mathrm{H}$ & C & & $\mathrm{H}$ & C & & $\mathrm{H}$ & C & \\
\hline
\end{tabular}

${ }^{*} \mathrm{C}$, clinic; $\mathrm{H}$, home; NR, not reported; SD, standard deviation; ${ }^{*} P<0.05$.

ableeding heavier than a normal menstrual bleed. 
Table 4. Acceptability of home-based and clinic-based medical abortion (MA) in studies included in systematic review comparing home-based and clinic-based medical abortion

\begin{tabular}{|c|c|c|c|c|c|c|c|c|c|c|c|c|c|c|c|}
\hline \multirow[t]{2}{*}{ Study } & \multicolumn{3}{|c|}{$\begin{array}{l}\text { Satisfied or } \\
\text { highly satisfied } \\
\text { with method (\%) }\end{array}$} & \multicolumn{3}{|c|}{$\begin{array}{l}\text { Would choose } \\
\text { method again } \\
(\%)\end{array}$} & \multicolumn{3}{|c|}{$\begin{array}{l}\text { Would } \\
\text { recommend } \\
\text { method to a } \\
\text { friend (\%) }\end{array}$} & \multicolumn{3}{|c|}{$\begin{array}{l}\text { Would select } \\
\text { home use of } \\
\text { miso for future } \\
\text { MA (\%) }\end{array}$} & \multicolumn{3}{|c|}{$\begin{array}{l}\text { Would select } \\
\text { clinic use for } \\
\text { future MA (\%) }\end{array}$} \\
\hline & $\mathrm{H}$ & $C$ & $M D$ & $\mathrm{H}$ & $C$ & $\mathrm{MD}$ & $\mathrm{H}$ & C & $\mathrm{MD}$ & $\mathrm{H}$ & C & $M D$ & $\mathrm{H}$ & ( & $\mathrm{MD}$ \\
\hline
\end{tabular}

${ }^{*} \mathrm{C}$, clinic; $\mathrm{H}$, home; $\mathrm{MD}$, mean difference; $\mathrm{NR}$, not reported; ${ }^{*} P<0.05$.

Table 5. Characteristics of studies

\begin{tabular}{|l|l|l|l|l|l|l|}
\hline Study & Methods & Participants & Interventions & Outcomes & Funding & Notes \\
\hline
\end{tabular}

Figure 1. Summary of study selection for systematic review of studies comparing home-based and clinicbased medical abortion (PRISMA flow diagram)

Figure 2. Forest plot comparing rates of successful abortion in women who underwent home-based compared to clinic-based medical abortion

\section{IMPLICATIONS}

Unsafe abortion is an important cause of global maternal mortality and morbidity. The COVID-19 global health crisis's impact on health systems, movement, and travel globally have the unintended consequences of restricting access to safe abortion care. One strategy to expand access to safe abortion and alleviate stress on already overburdened health facilities is to expand access to home-based medical abortion. This review updates the evidence on the effectiveness, safety, and acceptability of medical abortion performed at home. The results will have implications for health systems and legislators who may use the evidence to expand access to home-based medical abortion in the context of the COVID-19 emergency.

\section{REFERENCES}


1. WHO | Medical management of abortion [Internet]. WHO. World Health Organization; [cited 2020 Apr 14]. Available from: http://www.who.int/reproductivehealth/publications/medicalmanagement-abortion/en/

2. Ganatra B, Gerdts C, Rossier C, Johnson BR, Tunçalp Ö, Assifi A, et al. Global, regional, and subregional classification of abortions by safety, 2010-14: estimates from a Bayesian hierarchical model. The Lancet. 2017 Nov 25;390(10110):2372-81.

3. Singh S, Remez L, Sedgh G, Kwok L, Onda T. Abortion worldwide 2017: uneven Progress and unequal AccessAbortion worldwide 2017: uneven Progress and unequal Access. 2018;

4. Berer M. Medical abortion: issues of choice and acceptability. Reprod Health Matters. 2005;13(26):25-34.

5. Barot S. The Roadmap to Safe Abortion Worldwide: Lessons from New Global Trends on Incidence, Legality and Safety. 2018;21:6.

6. Fjerstad M, Trussell J, Sivin I, Lichtenberg ES, Cullins V. Rates of serious infection after changes in regimens for medical abortion. N Engl J Med. 2009;361(2):145-51.

7. Kulier R, Kapp N, Gülmezoglu AM, Hofmeyr GJ, Cheng L, Campana A. Medical methods for first trimester abortion. Cochrane Database Syst Rev. 2011;(11).

8. Rodriguez M, Seuc A, Kapp N, Von Hertzen H, Huong N, Wojdyla D, et al. Acceptability of misoprostol-only medical termination of pregnancy compared with vacuum aspiration: an international, multicentre trial. BJOG Int J Obstet Gynaecol. 2012;119(7):817-23.

9. Trussell J, Ellertson C. Estimating the efficacy of medical abortion. Contraception. 1999;60(3):119-35.

10. Winikoff B, Sivin I, Coyaji KJ, Cabezas E, Bilian X, Sujuan G, et al. Safety, efficacy, and acceptability of medical abortion in China, Cuba, and India: a comparative trial of mifepristonemisoprostol versus surgical abortion. Am J Obstet Gynecol. 1997;176(2):431-7.

11. Footman K, Keenan K, Reiss K, Reichwein B, Biswas P, Church K. Medical abortion provision by pharmacies and drug sellers in low-and middle-income countries: A systematic review. Stud Fam Plann. 2018;49(1):57-70.

12. Shannon C, Winikoff B. How much supervision is necessary for women taking mifepristone and misoprostol for early medical abortion? 2008;

13. Yarnall J, Swica Y, Winikoff B. Non-physician clinicians can safely provide first trimester medical abortion. Reprod Health Matters. 2009;17(33):61-9.

14. Medication Abortion Restrictions Burden Women and Providers-and Threaten U.S. Trend Toward Very Early Abortion [Internet]. Guttmacher Institute. 2013 [cited 2020 Apr 14]. Available from: 
https://www.guttmacher.org/gpr/2013/03/medication-abortion-restrictions-burden-women-andproviders-and-threaten-us-trend-toward

15. World Health Organization. Safe abortion: technical and policy guidance for health systems evidence summaries and grade tables. World Health Organization; 2012.

16. Cucinotta D, Vanelli M. WHO declares COVID-19 a pandemic. Acta Bio-Medica Atenei Parm. 2020;91(1):157-60.

17. Frank A. Phone booths, parades, and 10-minute test kits: How countries worldwide are fighting Covid-19 [Internet]. Vox. 2020 [cited 2020 Apr 14]. Available from: https://www.vox.com/science-andhealth/2020/3/22/21189889/coronavirus-covid-19-pandemic-response-south-korea-phillipines-italynicaragua-senegal-hong-kong

18. World Health Organization (WHO). Shortage of personal protective equipment endangering health workers worldwide: WHO; 2020 [March 11, 2020].

19. Schwirtz M. Nurses Die, Doctors Fall Sick and Panic Rises on Virus Front Lines. The New York Times [Internet]. 2020 Mar 30 [cited 2020 Apr 14]; Available from: https://www.nytimes.com/2020/03/30/nyregion/ny-coronavirus-doctors-sick.html

20. Cavallo JJ, Donoho DA, Forman HP. Hospital Capacity and Operations in the Coronavirus Disease 2019 (COVID-19) Pandemic-Planning for the Nth Patient. In American Medical Association; 2020. p. e200345-e200345.

21. Ho PC. Women's perceptions on medical abortion. Contraception. 2006;74(1):11-5.

22. Women in Northern Ireland 'will be able to have early abortions' amid coronavirus lockdown [Internet]. The Independent. 2020 [cited 2020 Apr 21]. Available from:

https://www.independent.co.uk/news/uk/home-news/northern-ireland-abortion-law-coronaviruswomen-pregnant-a9466336.html

23. New Abortion Guidance for Women in the U.K. Amid COVID-19 [Internet]. Time. [cited 2020 Apr 21]. Available from: https://time.com/5812433/abortion-coronavirus-outbreak-uk/

24. Ramaswamy A, Frederiksen B, 2020. State Action to Limit Abortion Access During the COVID-19 Pandemic [Internet]. The Henry J. Kaiser Family Foundation. 2020 [cited 2020 Apr 21]. Available from: https://www.kff.org/womens-health-policy/issue-brief/state-action-to-limit-abortion-access-during-thecovid-19-pandemic/

25. Provost C. Some governments are using coronavirus to restrict women's rights [Internet]. [cited 2020 Apr 23]. Available from: https://www.aljazeera.com/indepth/opinion/governments-coronavirusrestrict-women-rights-200412095859321.html

26. Joint Statement on Abortion Access During the COVID-19 Outbreak [Internet]. [cited 2020 Apr 21]. Available from: https://www.acog.org/en/News/News Releases/2020/03/Joint Statement on Abortion Access During the COVID 19 Outbreak 
27. Ngo TD, Park MH, Shakur H, Free C. Comparative effectiveness, safety and acceptability of medical abortion at home and in a clinic: a systematic review. Bull World Health Organ. 2011;89:360-70.

28. Gambir K, Kim C, Necastro KA, Ganatra B, Ngo TD. Self-administered versus provideradministered medical abortion. Cochrane Database Syst Rev. 2020;(3).

29. Raymond EG, Harrison MS, Weaver MA. Efficacy of Misoprostol alone for first-trimester medical Abortion: A systematic Review. Obstet Gynecol. 2019;133(1):137-47.

30. Shrestha D, Aryal S, Sharma B. Safety, Efficacy and Acceptability of Early First Trimester Abortion using Oral Mifepristone and Sublingual Misoprostol. J Nepal Health Res Counc. 2018;16(3):269-73.

31. Hyman A, Blanchard K, Coeytaux F, Grossman D, Teixeira A. Misoprostol in women's hands: a harm reduction strategy for unsafe abortion. Contraception. 2013 Feb;87(2):128-30.

32. Kero A, Wulff M, Lalos A. Home abortion implies radical changes for women. Eur J Contracept Reprod Health Care Off J Eur Soc Contracept. 2009 Oct;14(5):324-33.

33. Platais I, Tsereteli T, Grebennikova G, Lotarevich T, Winikoff B. Prospective study of home use of mifepristone and misoprostol for medical abortion up to 10 weeks of pregnancy in Kazakhstan. Int J Gynaecol Obstet Off Organ Int Fed Gynaecol Obstet. 2016 Sep;134(3):268-71.

34. Early medical abortion with self-administered low-dose mifepristone in combination with misoprostol - Song - 2018 - Journal of Obstetrics and Gynaecology Research - Wiley Online Library [Internet]. [cited 2020 Apr 14]. Available from:

https://obgyn.onlinelibrary.wiley.com/doi/full/10.1111/jog.13716

35. Tan Y-L, Singh K, Tan KH, Gosavi A, Koh D, Abbas D, et al. Acceptability and feasibility of outpatient medical abortion with mifepristone and misoprostol up to 70 days gestation in Singapore. Eur J Obstet Gynecol Reprod Biol. 2018 Oct;229:144-7.

36. Kahn JG, Becker BJ, Maclsaa L, Amory JK, Neuhaus J, Olkin I, et al. The efficacy of medical abortion: a meta-analysis. Contraception. 2000;61(1):29-40.

37. Higgins JP, Green S. Cochrane Handbook for Systematic Reviews of Interventions Version 5.1. 0 [updated March 2011]. The Cochrane Collaboration, 2011. Available from www. cochrane-handbook. org. Accessed August. 2011;29.

38. Moher D, Liberati A, Tetzlaff J, Altman DG. Preferred reporting items for systematic reviews and meta-analyses: the PRISMA statement. Ann Intern Med. 2009;151(4):264-9.

39. What is GRADE? | BMJ Best Practice [Internet]. [cited 2020 Apr 24]. Available from: https://bestpractice.bmj.com/info/us/toolkit/learn-ebm/what-is-grade/

40. Deeks JJ, Higgins JP, Altman DG, Cochrane Statistical Methods Group. Analysing data and undertaking meta-analyses. Cochrane Handb Syst Rev Interv. 2019;241-84.

41. Review Manager Web (RevMan Web.). The Cochrane Collaboration; 2019. 